\title{
Formation of a benzothiazine via the reaction of ortho-halo sulfoximines with copper salts
}

\author{
Aswinkumar Garimallaprabhakaran, Xuechuan Hong ${ }^{1}$ and Michael Harmata* \\ Department of Chemistry, University of Missouri-Columbia, Columbia, Missouri 65211, USA \\ E-mail: harmatam@missouri.edu
}

\begin{abstract}
The formation of an interesting benzothiazine from the reaction of $S$-(o-halophenyl)-S-methyl sulfoximines in the presence of copper salts is reported. The overall yield is $27 \%$ over three steps from commercially available 2-halothioanisoles in the best case. The product's structure was confirmed by spectroscopic and X-ray crystal analysis. The benzothiazine shows fluorescent properties.
\end{abstract}

Keywords: Benzothiazine, sulfoximine, copper catalysis

\section{Introduction}

In the course of our continuing work on the preparation of benzothiazines, ${ }^{2}$ we have pursued various studies on the $\mathrm{N}$-arylation of sulfoximines. ${ }^{3}$ The Bolm group has made significant contributions to this area and was the first to establish a palladium-catalyzed N-arylation of sulfoximines. ${ }^{4}$ They have also shown that $N$-arylation can be catalyzed or mediated by copper, iron and nickel species and that a variety of electrophilic species besides aryl bromides can be used in the process. ${ }^{5}$ More recently, boronic acids ${ }^{6}$ and a $\mathrm{C}-\mathrm{H}$ activation ${ }^{7}$ process have been introduced for this $N$-arylation.

\section{Results and Discussion}

We became interested in the $N$-arylation of sulfoximine 1a with itself, a process that might result in the formation of the cyclic bis-sulfoximine $\mathbf{3}$, a potentially useful chiral ligand and a progenitor of what could be a family of ligands (Scheme 1).

When treated with a palladium catalyst under conditions that would result in $\mathrm{N}$-arylation of the des-bromo analogue of $\mathbf{1 a}$ with bromobenzene, ${ }^{4} \mathbf{1 a}$ was unreactive with respect to selfcoupling. ${ }^{8}$ It should be noted, however, that we have reported that 1a undergoes Sonogashira 
coupling with various alkynes, suggesting that such compounds can readily engage in oxidative addition with $\operatorname{Pd}(0)$ species. ${ }^{9}$ We have speculated that metallocycles might arise from the

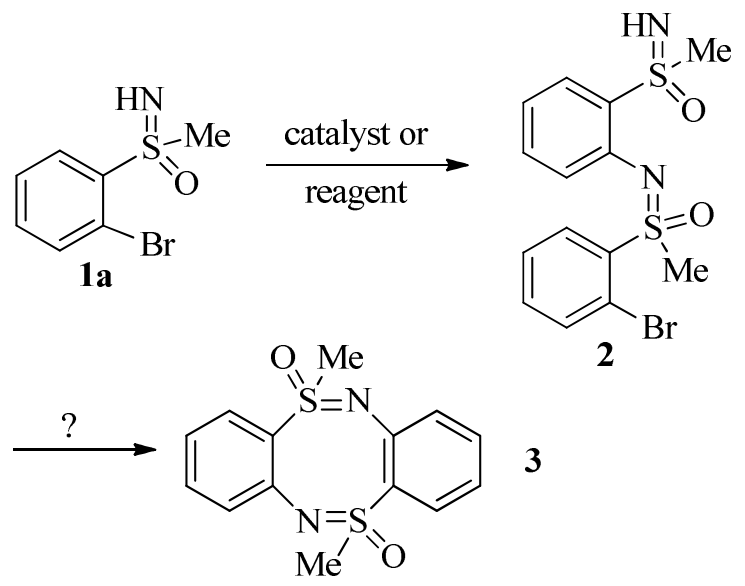

Scheme 1. Proposed formation of the cyclic bis-sulfoximine 3.

reaction of 1a with certain metals, but have no definitive evidence as to the existence of such species, much less data about their reactivity. In any case, copper salts were attractive as an alternative catalyst for this process, especially given their cost relative to palladium reagents and their precedented use for the $\mathrm{N}$-arylation of $\mathrm{NH}$ sulfoximines. ${ }^{5 a}$ We thus studied the reaction of 1a with copper salts. Compound 1a was treated with 1 equivalent of $\mathrm{CuI}$ and 2.5 equivalents of $\mathrm{Cs}_{2} \mathrm{CO}_{3}$ in DMSO for 12 hours at $110{ }^{\circ} \mathrm{C}$. After consumption of the starting material, benzothiazine 4 was isolated in 33\% yield. Though other products were obtained, all were complicated mixtures. ${ }^{10}$

This result observed was unexpected, though the benzothiazine $\mathbf{4}$ is, in fact, known. Hori and coworkers reported its synthesis over 30 years ago, but by a route completely different from that described herein. ${ }^{11}$

We attempted to optimize the synthesis of $\mathbf{4}$, since overall the process we discovered is in principle more efficient than Hori's route. To that end, we decided not only to investigate the chemistry of $\mathbf{1 a},{ }^{9}$ but also of the chlorine and iodine analogues $\mathbf{1} \mathbf{b}^{12}$ and $\mathbf{1 c}$. The synthesis of all 3 congeners is shown in Scheme 2 and followed a standard protocol for the synthesis of sulfoximines of this general type. ${ }^{13}$

As shown in Table 1, variations in the amounts of the copper iodide mediator and the amount of base did not have a significant effect on the yield of the process, the best yield being $40 \%$ (Table 1, entry 5). Table 2 shows that of the simple carbonate bases tested, cesium carbonate was the best performer and the dipolar aprotic solvent DMSO was the best solvent for the reaction, though other dipolar aprotic solvents were not examined. It may be that the solubility of the copper salt plays a role in the efficiency of the reaction. 

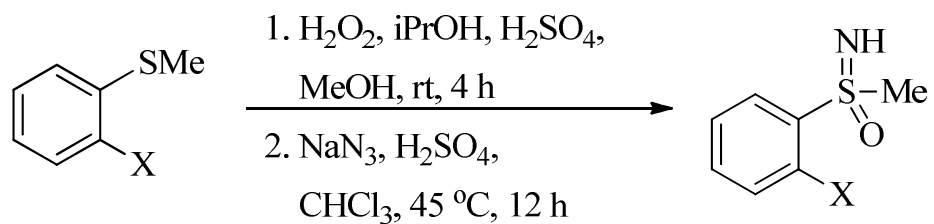

1a, $X=\mathrm{Br}, 68 \%$
1b, $X=\mathrm{Cl}, 63 \%$
1c, $X=\mathrm{I}, 37 \%$

Scheme 2. Synthesis of $o$-halo sulfoximines.

Since neither variation in temperature ${ }^{14}$ or time, nor changes in base and solvent, (Tables 1 and 2) resulted in improved yields of the product, we chose those conditions affording the best yield (Table 1, entry 5) as the "optimal" reaction conditions and screened several diamines as additives based on Buchwald's observation that the best performing ligands in copper-catalyzed C-N coupling reactions are 1,2-diamines. ${ }^{15}$ However, neither the addition of 2 equivalents of ethylenediamine, $N, N, N^{\prime}, N^{\prime}$-tetramethylethylenediamine, $N, N$-dimethylethylenediamine, 2,2bipyridine nor phenanthroline led to any significant changes in the outcome of the reaction.

Table 1. Effect of catalyst and base loading on the copper-mediated self-condensation of sulfoximine $1 \mathbf{a}^{\mathrm{a}}$

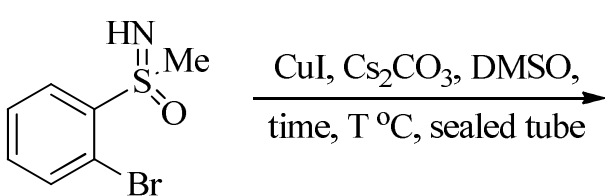

$1 \mathrm{a}$

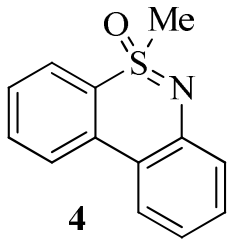

$\mathrm{T}^{\circ} \mathrm{C}$

Yield (\%)

Time, h equiv

124

1

24

12

12

12

24

12

12
150

150

115

115

115

150

115

115

$0^{\mathrm{b}}$

2

10

15

40

32

35

2.5

200

${ }^{\mathrm{a}}$ Reaction conditions: 1a $(1 \mathrm{mmol})$ in DMSO $(0.4 \mathrm{M})$; sealed tube. ${ }^{\mathrm{b}}$ Recovered starting material.

A survey of copper sources also revealed that $\mathrm{CuI}$ was the preferred mediator of the reaction (Table 3). Copper bromide and chloride were poorer promoters of the reaction, but not that much 
different from copper iodide. Addition of zinc and copper iodide lowered the yield to zero depending on the amount of zinc added (Table 3, entries 6 and 7). The hope was that formation of an organozinc species ${ }^{16}$ would be followed by transmetalation to copper, facilitating the reaction. Since the use of copper acetate and copper oxide has been reported for the $N$-arylation of sulfoximines, ${ }^{5 c, 6}$ we tested these reagents, but the results were inferior to that obtained with copper iodide (Table 3, entries 8 and 9).

Table 2. Effect of solvent and base on the copper-mediated self-condensation of sulfoximine $\mathbf{1 a}^{\mathrm{a}}$

\begin{tabular}{cccc}
\hline Entry & Base & Solvent & Yield (\%) \\
\hline 1 & $\mathrm{Cs}_{2} \mathrm{CO}_{3}$ & toluene & 4 \\
2 & $\mathrm{Cs}_{2} \mathrm{CO}_{3}$ & $o$-xylene & 10 \\
3 & $\mathrm{Cs}_{2} \mathrm{CO}_{3}$ & dioxane & 23 \\
4 & $\mathrm{Cs}_{2} \mathrm{CO}_{3}$ & DMSO & 38 \\
5 & $\mathrm{~K}_{2} \mathrm{CO}_{3}$ & DMSO & 20 \\
6 & $\mathrm{Na}_{2} \mathrm{CO}_{3}$ & DMSO & 18 \\
\hline
\end{tabular}

${ }^{\mathrm{a}}$ Reaction conditions: $\mathrm{CuI}(1 \mathrm{mmol})$, base $(2.5 \mathrm{mmol})$, sulfoximine $\mathbf{1 a}(1 \mathrm{mmol})$ in solvent $(0.4$ M) at $115^{\circ} \mathrm{C}$ for $12 \mathrm{~h}$ in a sealed tube.

Table 3. Screening of copper sources for the reaction of $1 \mathbf{a}^{\mathrm{a}}$

\begin{tabular}{cccc}
\hline Entry & Reactant & $\mathrm{Cu}$ source & Yield 4 (\%) \\
\hline 1 & $\mathbf{1 a}$ & $\mathrm{CuI}$ & 40 \\
2 & $\mathbf{1 b}$ & $\mathrm{CuCl}$ & 22 \\
3 & $\mathbf{1 c}$ & $\mathrm{CuBr}$ & 20 \\
4 & $\mathbf{1 a}$ & $\mathrm{CuCl}$ & 30 \\
5 & $\mathbf{1 a}$ & $\mathrm{CuBr}$ & 29 \\
6 & $\mathbf{1 a}$ & $\mathrm{Zn} / \mathrm{CuI}(1: 10)$ & 24 \\
7 & $\mathbf{1 a}$ & $\mathrm{Zn} / \mathrm{CuI}(1: 1)$ & $0^{\mathrm{b}}$ \\
8 & $\mathbf{1 a}$ & $\mathrm{Cu}$ & 10 \\
9 & $\mathbf{1 a}$ & $\mathrm{Cu}(\mathrm{OAc})_{2}$ & 12 \\
\hline
\end{tabular}

${ }^{\mathrm{a}}$ Reaction conditions: Copper source $(1 \mathrm{mmol})$, base $(2.5 \mathrm{mmol})$, sulfoximine 1 (1 mmol) in $\operatorname{DMSO}(0.4 \mathrm{M})$ at $115^{\circ} \mathrm{C}$ for $12 \mathrm{~h} .{ }^{\mathrm{b}}$ Recovered starting material.

As the "best" conditions for the process seemed unchanged by these studies, we examined the reaction of $\mathbf{1 b}$ and $\mathbf{1 c}$ to assess the effect of the ortho-halogen on the sulfoximine on the course of the reaction. The results are shown in Table 4. Although one might expect a more considerable difference in yields, neither the chloride $\mathbf{1 b}$ or the iodide $\mathbf{1 c}$ was significantly worse as a substrate in the reaction than 1a, although we were surprised to find that $\mathbf{1 c}$ was not better. 
Table 4. Reactivity of $o$-halo sulfoximines 1a-c in presence of copper iodide ${ }^{\mathrm{a}}$

\begin{tabular}{ccc}
\hline Entry & Sulfoximine & Yield 4 $(\%)$ \\
\hline 1 & 1a & 40 \\
2 & $\mathbf{1 b}$ & 28 \\
3 & 1c & 32 \\
\hline
\end{tabular}

${ }^{\mathrm{a}}$ Reaction conditions: $\mathrm{CuI}(1 \mathrm{mmol}), \mathrm{Cs}_{2} \mathrm{CO}_{3}(2.5 \mathrm{mmol})$, sulfoximine $(1 \mathrm{mmol})$ in DMSO $(0.4$ M) at $115^{\circ} \mathrm{C}$ for $12 \mathrm{~h}$.

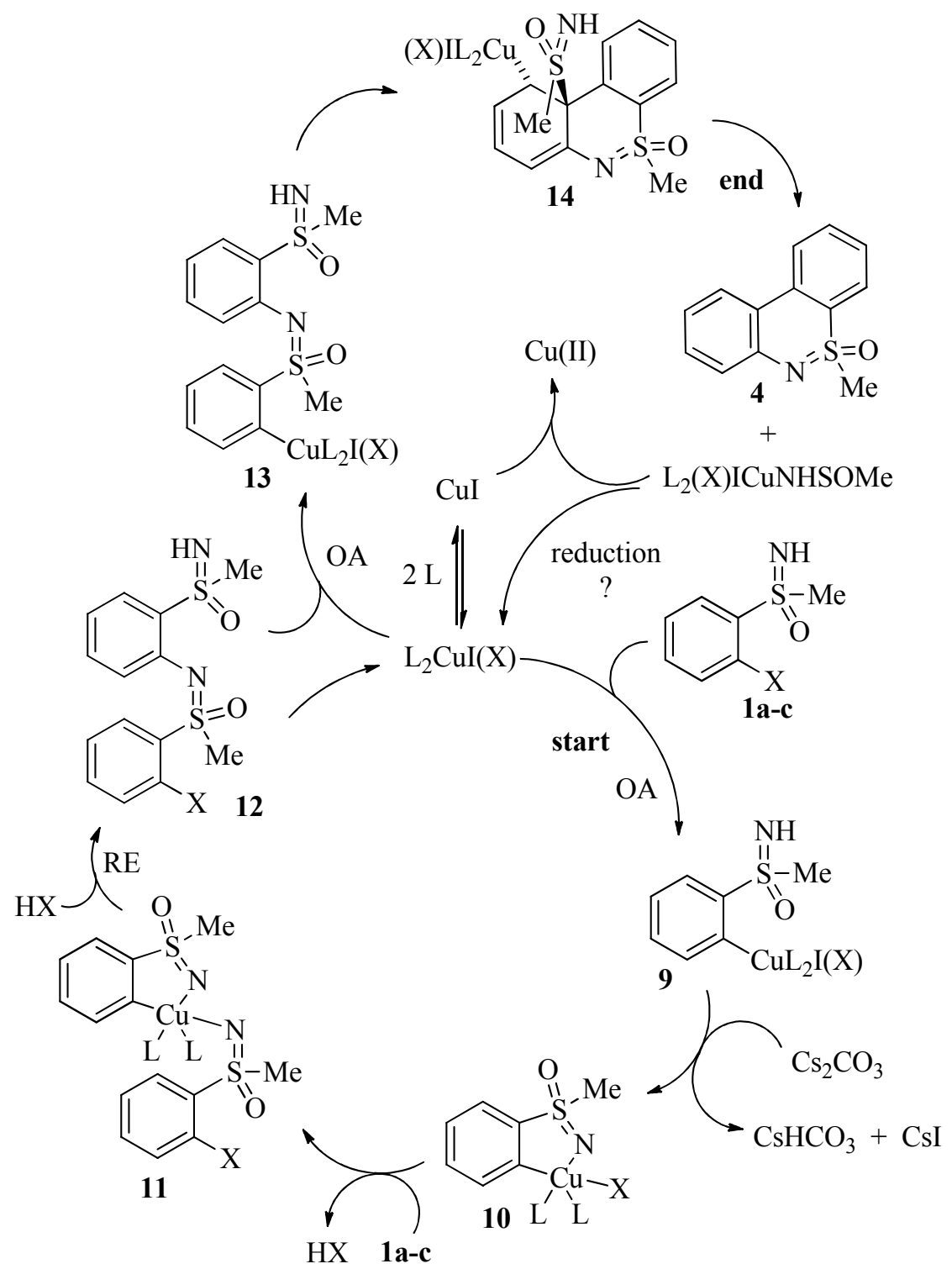

Scheme 3. Proposed mechanism for the formation of $\mathbf{4}$ from $\mathbf{1 .}$ 
The mechanism for this reaction is not known, but we speculate based on literature precedent that a reasonable pathway for the reaction is that shown in Scheme $3 .{ }^{17}$ Thus, oxidative addition (OA) of $\mathrm{CuI}$ to $\mathbf{1}$ results in the formation of $9 .{ }^{18}$ In the presence of base, it seems likely that metallocycle formation would proceed to give 10. Substitution of a labile ligand on copper, either iodide originating from $\mathrm{CuI}$ or " $\mathrm{X}$ " originating from $\mathbf{1}$, by additional $\mathbf{1}$, would result in the formation of 11. Reductive elimination (RE) would afford $\mathbf{1 2}$ and regenerate a copper (I) species. So, in principle, this cycle is catalytic.

Another oxidative addition into the $\mathrm{C}-\mathrm{X}$ bond of $\mathbf{1 2}$ would give the intermediate 13. An intramolecular carbometalation would lead to the cyclic intermediate 14. Though this temporarily disrupts aromaticity, it provides a good rationalization for the loss of one of the sulfur groups through $\beta$-elimination, which leads directly to 4 . A copper (III) species remains, which could disproportionate with copper (I) compounds, rendering the process non-catalytic.

In cogitating our proposed mechanism, we thought it might be possible to take advantage of chemistry based on the interception of benzynes by organopalladium species, as in the annulation of ortho-halobenzaldehydes as reported by Larock. ${ }^{19}$ We thus decided to apply this chemistry to the synthesis of 4. The results are shown in Table 5. Thus, treatment of 1a-c with $\mathbf{1 5}$ in the presence of $\mathrm{Pd}_{2}(\mathrm{dba})_{3}, \mathrm{P}(\mathrm{o} \text {-tolyl })_{3}$ and excess $\mathrm{CsF}$ resulted in the formation of $\mathbf{4}$ in low yield. Changes to the catalyst loading $(10 \%, 15 \%, 20 \%$ Pd) and ligand $(10 \%, 15 \%, 20 \%)$ did not improve the yield of the reaction. Similarly, changes to the amount of base $(5,10$ equiv) and elevated temperatures $\left(135{ }^{\circ} \mathrm{C}, 150{ }^{\circ} \mathrm{C}\right)$ did not result in improved yields. It is interesting, however, that the iodide 1c performed the best in this particular reaction sequence. Unfortunately, no clean side products in this process could be isolated, save recovered starting material (ca. 20\%).

Table 5. Palladium-catalyzed of 1a-c with 15 to form 4

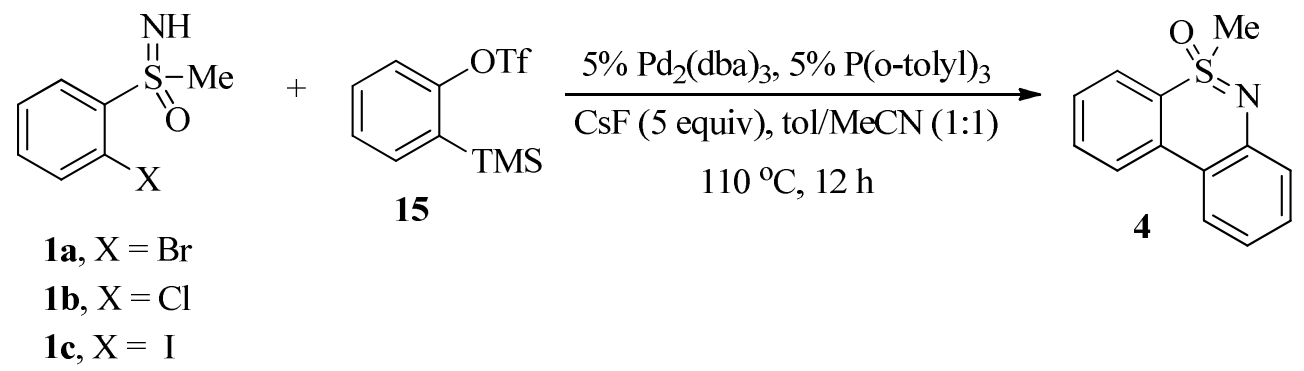

\begin{tabular}{ccc}
\hline Entry & Sulfoximine & Yield $\mathbf{4}(\%)$ \\
\hline 1 & $\mathbf{1 a}$ & 24 \\
2 & $\mathbf{1 b}$ & 20 \\
3 & $\mathbf{1 c}$ & 30 \\
\hline
\end{tabular}




\section{Conclusions}

In summary, a copper-mediated and palladium-catalyzed method for the synthesis of a benzofused benzothiazine from $o$-halo sulfoximines has been described. The low yields are attributed to unidentified side reactions of the $o$-halo sulfoximines. This chemistry is not yet synthetically useful, yet it compares well to the known synthesis of 4 . Hori produced 4 in $21 \%$ overall yield in 4 steps. ${ }^{11}$ We obtained 4 in $27 \%$ yield over three steps from $o$-bromothioanisole. Finally, it is worth noting that $\mathbf{4}$ is fluorescent and members of this class of compound may be useful in the development of fluorescent sensors. ${ }^{20}$

\section{Experimental Section}

General. All reactions were carried out under argon atmosphere in a flame dried sealed tube. $\mathrm{CuI}$ was used as purchased from Acros organics. DMSO was purchased from Drysolv ${ }^{\circledR}$ Acros organics and distilled over $\mathrm{CaH}_{2}$. Toluene and acetonitrile are distilled over $\mathrm{CaH}_{2}$. The synthesis of all 3 congeners is shown in Scheme 3 and followed a standard protocol for the synthesis of sulfoximines of this general type. ${ }^{21}$ The reaction mixture was concentrated by using a rotary evaporator attached to a water aspirator. Residual solvents were usually removed under reduced pressure using vacuum pump (approximately $1 \mathrm{mmHg}$ ).

Flash chromatographic separations were carried out on Silicyle ultra-pure silica gel (230-400 mesh) with ACS reagent grade solvents. Analytical thin chromatography was performed on EM reagent $0.25 \mathrm{~nm}$ silicagel $60-\mathrm{F}$ plates with F-254 indicator. Compounds were visualized under UV light. Melting points were determined with a Fisher-Johns Hot stage melting point apparatus and were not corrected.

${ }^{1} \mathrm{H}$ NMR spectra were recorded on a Bruker DRX-500 at $500 \mathrm{MHz}$ as $\mathrm{CDCl}_{3}$ solutions with tetramethylsilane $(\delta=0 \mathrm{ppm})$ as the internal standard. ${ }^{13} \mathrm{C}$ NMR spectra were recorded on the same instrument at $125 \mathrm{MHz}$ with $\mathrm{CDCl}_{3}(\delta=77.0 \mathrm{ppm})$ as the internal reference. Chemical shifts are reported in $\mathrm{ppm}$ from tetramethylsilane $(0.0 \mathrm{ppm})$. Multiplicities are reported as $\mathrm{s}$ (singlet), b (broad), d (doublet), t (triplet), q (quartet), $\mathrm{m}$ (multiplet) and dd ( doublet of doublet), etc. All the reaction yields were reported based on the best result, if not stated otherwise.

A round-bottomed flask was charged with (2-bromophenyl)methyl sulfide ( $8.9 \mathrm{~g}, 43.93 \mathrm{mmol}$ ), $\mathrm{MeOH}(125 \mathrm{~mL})$ and a mixture of sulfuric acid and 2-propanol $\left(12.7 \mathrm{~g}, 4.4 \% \mathrm{w} / \mathrm{w} \mathrm{H}_{2} \mathrm{SO}_{4} / 2-\right.$ propanol). $3.5 \mathrm{M} \mathrm{H}_{2} \mathrm{O}_{2}(15.4 \mathrm{~mL}, 15.38 \mathrm{mmol}, 1$ equiv) was added at once to the stirred mixture. After $4 \mathrm{~h}$, the reaction was complete, and water $(500 \mathrm{~mL})$ was added to the reaction mixture. The aqueous layer was saturated with $\mathrm{NaCl}$ and extracted with $\mathrm{CHCl}_{3}(3 \times 150 \mathrm{~mL})$. The combined organic layers were dried over $\mathrm{MgSO}_{4}$, and evaporated to give the pure sulfoxide for the next step reaction. To a round-bottomed flask equipped with a condenser, an addition funnel, and a magnetic stir bar, a mixture of the above sulfoxide, sodium azide $(4.89 \mathrm{~g}, 75.2 \mathrm{mmol})$, and $100 \mathrm{~mL}$ of chloroform $(0.5 \mathrm{M})$ were added and mixture was cooled in an ice bath. To this slurry, 
$13.44 \mathrm{~mL}$ of concentrated sulfuric acid was added over $15 \mathrm{~min}$ with stirring. The mixture was then carefully warmed to $45{ }^{\circ} \mathrm{C}$ and heated for $12 \mathrm{~h}$. After cooling, $100 \mathrm{~mL}$ of ice water was added. After all of the salts were dissolved, the $\mathrm{CHCl}_{3}$ layer was separated and the aqueous layer was reextracted with $100 \mathrm{~mL}$ of $\mathrm{CHCl}_{3}$. The aqueous layer was made slightly alkaline with a $20 \%$ sodium hydroxide solution and extracted twice with $3 \times 100 \mathrm{~mL}$ of $\mathrm{CHCl}_{3}$. The combined extracts were dried over magnesium sulfate and evaporation of the solvent yielded $6.8 \mathrm{~g}(68 \%$, two steps) of the sulfoximine 1a as a pale white solid. NMR data matched that published in the literature. $^{9}$

S-(2-Chlorophenyl)-S-methyl sulfoximine (1b). (63\% in two steps following the above procedure from commercially available S-(2-chlorophenyl)-S-methyl sulfide) white solid from $50 \%$ ethyl acetate/hexanes, $\mathrm{mp} 97-99^{\circ} \mathrm{C} ; \mathrm{R}_{\mathrm{f}}=0.2$ (50\% ethyl acetate/hexanes); IR $(\mathrm{KBr}) \vee 3267$, 3123, 2925, 1573, 1450, 1230, 1016, 952, $755 \mathrm{~cm}^{-1} ;{ }^{1} \mathrm{H}-\mathrm{NMR}\left(500 \mathrm{MHz}, \mathrm{CDCl}_{3}\right) \delta 8.18(\mathrm{dd}, J=$ 8.0, $1.5 \mathrm{~Hz}, 1 \mathrm{H}), \delta 7.55-7.53(\mathrm{~m}, 2 \mathrm{H}), \delta 7.46(\mathrm{dt}, J=8.0,1.5 \mathrm{~Hz}, 1 \mathrm{H}), 3.32(\mathrm{~s}, 3 \mathrm{H}), 2.91(\mathrm{~b}, 1 \mathrm{H})$; ${ }^{13} \mathrm{C}-\mathrm{NMR}\left(125 \mathrm{MHz}, \mathrm{CDCl}_{3}\right) \delta 140.9,133.9,132.2,131.9,130.5,127.3,43.3$; HRMS calculated for $\left(\mathrm{C}_{7} \mathrm{H}_{8} \mathrm{ClNOS}\right)_{2} \mathrm{Na}^{+}: 400.9922$, found: 400.9922 .

S-(2-Iodophenyl)-S-methyl sulfoximine (1c). (37\% in two steps following the above procedure from commercially available (2-iodophenyl)methyl sulfide, brown oil, $\mathrm{R}_{\mathrm{f}}=0.2$ (50\% ethyl acetate/hexanes), IR $\left(\mathrm{CHCl}_{3}\right) \vee 3250,3140,2925,1567,1440,1226,1016,999,749 \mathrm{~cm}^{-1} ;{ }^{1} \mathrm{H}-$ NMR $\left(500 \mathrm{MHz}, \mathrm{CDCl}_{3}\right) \delta 8.32(\mathrm{dd}, J=8.0,1.5 \mathrm{~Hz}, 1 \mathrm{H}), \delta 8.13(\mathrm{dd}, J=8.0,1.5 \mathrm{~Hz}, 1 \mathrm{H}), \delta 7.55$ $(\mathrm{dt}, J=8.0,1.5 \mathrm{~Hz}, 1 \mathrm{H}), \delta 7.22(\mathrm{dt}, J=8.0,1.5 \mathrm{~Hz}, 1 \mathrm{H}), 3.29(\mathrm{~s}, 3 \mathrm{H}), 2.76(\mathrm{~b}, 1 \mathrm{H}) ;{ }^{13} \mathrm{C}-\mathrm{NMR}$ $\left(125 \mathrm{MHz}, \mathrm{CDCl}_{3}\right) \delta 145.3,142.9,133.6,130.3,128.8$, 93.0, 42.3; HRMS calculated for $\left(\mathrm{C}_{7} \mathrm{H}_{8} \mathrm{INOS}\right)_{2} \mathrm{Na}^{+}: 584.8634$, found: 584.8631 .

\section{General procedure for the reaction of (1a-c) with copper salts}

A flame-dried, $50 \mathrm{~mL}$ sealed tube fitted with a screw cap and a stir bar was charged with sulfoximine 1a $(2.5 \mathrm{~g}, 10 \mathrm{mmol})$ in dimethyl sulfoxide $(25 \mathrm{~mL}, 0.4 \mathrm{M})$. Copper iodide $(1.97 \mathrm{~g}$, $10 \mathrm{mmol}$ ) and cesium carbonate, (8.68 g, $26 \mathrm{mmol}$ ) were added under an argon atmosphere, and the mixture was degassed by bubbling with argon for $15 \mathrm{~min}$ with stirring. The tube was sealed and heated to $115^{\circ} \mathrm{C}$ in an oil bath. The greenish solution changed to light blue at around $80{ }^{\circ} \mathrm{C}$. This solution was further heated to $115{ }^{\circ} \mathrm{C}$ for $12 \mathrm{~h}$. After cooling to room temperature, the reaction mixture was neutralized with hydrochloric acid solution $(125 \mathrm{~mL}, 1 \mathrm{M})$ and extracted with ethyl acetate $(3 \times 125 \mathrm{~mL})$. The organic layers were collected, dried with magnesium sulfate, filtered and the solvent was removed under vacuum. The crude product was then purified by flash column chromatography using $50 \%$ ethyl acetate/hexanes to afford $480 \mathrm{mg}$ of pure 4 .

\section{General procedure for the palladium-catalyzed annulation of $o$-halo sulfoximines}

A flame-dried, $10 \mathrm{~mL}$ sealed tube fitted with a screw cap and a stir bar was charged with sulfoximine $1 \mathrm{a}$ (100 mg, $0.43 \mathrm{mmol}), \mathrm{Pd}_{2} \mathrm{dba}_{3}(19.7 \mathrm{mg}, 0.022 \mathrm{mmol}), \mathrm{P}(o \text {-tolyl })_{3}(6.5 \mathrm{mg}, 0.022$ $\mathrm{mmol})$, 2-(trimethylsilyl)phenyltrifluoromethanesulfonate $(640 \mathrm{mg}, 2.15 \mathrm{mmol})$, cesium fluoride (324 mg, $2.15 \mathrm{mmol})$, and toluene/acetonitrile $(1: 1,5.8 \mathrm{~mL}, 0.075 \mathrm{M})$ under an argon 
atmosphere. The mixture was degassed by bubbling with argon for 15 min with stirring. The tube was sealed and heated at $110{ }^{\circ} \mathrm{C}$ for $16 \mathrm{~h}$. After cooling to room temperature, the reaction mixture was washed with brine $(10 \mathrm{~mL})$ and extracted with ethyl acetate $(3 \times 10 \mathrm{~mL})$. The combined extracts were dried with magnesium sulfate. Filtration and removal of solvent afforded crude product. This was purified by flash column chromatography using $50 \%$ ethyl acetate/hexanes to afford $14.2 \mathrm{mg}(24 \%)$ of 4 .

5-Methyl-4a,10b-dihydro-5 $\lambda^{4}$-dibenzo[c,e][1,2]thiazine 5-oxide (4). Dull white solid from $50 \%$ ethyl acetate/hexanes, $\mathrm{mp} 132-33{ }^{\circ} \mathrm{C} ; \mathrm{R}_{\mathrm{f}}=0.33(50 \%$ ethyl acetate/hexanes); IR (KBr) $v$ 3060, 3029, 2918, 1599, 1473, 1190, 1016, $801 \mathrm{~cm}^{-1} ;{ }^{1} \mathrm{H}-\mathrm{NMR}\left(500 \mathrm{MHz}, \mathrm{CDCl}_{3}\right) \delta 8.20(\mathrm{~d}, J=$ $8.5 \mathrm{~Hz}, 1 \mathrm{H}), 8.00(\mathrm{~d}, J=8.5 \mathrm{~Hz}, 1 \mathrm{H}), 7.92(\mathrm{~d}, J=8.0 \mathrm{~Hz}, 1 \mathrm{H}), 7.74(\mathrm{t}, J=7.5 \mathrm{~Hz}, 1 \mathrm{H}), 7.59(\mathrm{t}, J$ $=7.5 \mathrm{~Hz}, 1 \mathrm{H}), 7.39(\mathrm{t}, J=7.5 \mathrm{~Hz}, 1 \mathrm{H}), 7.27(\mathrm{~d}, J=8.5 \mathrm{~Hz}, 1 \mathrm{H}), 7.09$ (t, $J=7.5 \mathrm{~Hz}, 1 \mathrm{H}), 3.53(\mathrm{~s}$, $3 \mathrm{H}) ;{ }^{13} \mathrm{C}-\mathrm{NMR}\left(125 \mathrm{MHz}, \mathrm{CDCl}_{3}\right) \delta 142.7,133.9,132.8,130.6,127.8,124.78,123.8,123.4$, 120.7, 117.3 44.0; HRMS calculated for $\left(\mathrm{C}_{13} \mathrm{H}_{11} \mathrm{NOS}\right) \mathrm{Na}^{+}: 252.0453$, found: 252.0450 .

Crystal Structure of compound (4). $\mathrm{C}_{13} \mathrm{H}_{11} \mathrm{NOS}, M=229.29$; a block crystal $(0.35 \mathrm{x} 0.25 \mathrm{x}$ $0.15 \mathrm{~mm}), T=173(2) \mathrm{K}, \lambda=0.71073 \AA$, monoclinic, space group: $\mathrm{P} 21 / \mathrm{n}, a=8.3878(5) \AA, b=$ 11.6377(7) $\AA, c=10.9212(7) \AA, V=1065.89(11) \mathrm{A}^{\wedge} 3,7503$ total reflections, 2346 unique, Rint $=0.0287 R 1=0.0448(\mathrm{I}>2 \mathrm{~s}), \mathrm{w} R 2=0.0897$, Flack parameter: $0.06(10)$. Please see CCDC 822212.

\section{Acknowledgements}

We are grateful to the Petroleum Research Fund, administered by the American Chemical Society, and to the National Science Foundation for support of this work. We thank Dr. Charles L. Barnes for the acquisition of X-ray data.

\section{References and Notes}

1. Current Address: Key Laboratory of Combinatorial Biosynthesis and Drug Discovery, Wuhan University School of Pharmaceutical Sciences, Wuhan, 430071, P. R. China

2. (a) Hong, X.; Harmata, M. Prog. Het. Chem. 2008, 19, 1.

3. (a) Harmata, M.; Hong, X.; Ghosh, S. K. Tetrahedron Lett. 2004, 45, 5233. (b) Yongpruksa, N.; Calkins, N. L.; Harmata, M. Chem. Commun. 2011, 47, 7665.

4. (a) Bolm, C.; Hildebrand, J. P. Tetrahedron Lett. 1998, 39, 5731. (b) Bolm, C.; Hildebrand, J. P. J. Org. Chem. 2000, 65, 169.

5. (a) Sedelmeier, J.; Bolm, C. J. Org. Chem. 2005, 70, 6904. (b) Cho, G. Y.; Remy, P.; Jansson, J.; Moessner, C.; Bolm, C. Org. Lett. 2004, 6, 3293. (c) Correa, A.; Bolm, C. Adv. Synth. Catal. 2007, 349, 2673. (d) Bolm, C.; Hildebrand, J. P.; Rudolph, J. Synthesis 2000, 911. (e) Xie, R.; Fu, H.; Ling, Y. Chem Commun. 2011, 47, 8976. 
6. Moessner, C.; Bolm, C. Org. Lett. 2005, 7, 2667.

7. Miyasaka, M.; Hirano, K.; Satoh, T.; Kowalczyk, R.; Bolm, C.; Miura, M. Org. Lett. 2011, 13, 359.

8. Related experiments with $\mathbf{1 b}$ and $\mathbf{1 c}$ yielded the same result.

9. Harmata, M.; Rayanil, K.-o.; Gomes, M. G.; Zheng, P.; Calkins, N. L.; Kim, S.-Y.; Fan, Y.; Bumbu, V.; Lee, D. R.; Wacharasindhu, S.; Hong, X. Org. Lett. 2005, 7, 143.

10. A coworker has reported that this reaction worked in $75 \%$ yield, but we were never able to reproduce this result.

11. (a) Hori, M.; Kataoka, T.; Shimizu, H.; Matsuo, K. Tetrahedron Lett. 1979, 3969. (b) Shimizu, H.; Matsuo, K.; kataoka, T.; Hori, M. Chem. Pharm. Bull. 1984, 32, 4360. (c) Shimazu, H.; Ikedo, K.; Hamada, K.; Ozawa, M.; Matsumoto, H.; Kamata, K.; Nakamura, H.; Ji, M.; Kataoka, T.; Hori, M. J. Chem. Soc., Perkin Trans I 1991, 1733.

12. Mutti, R.; Winternitz, P. Synthesis 1986, 426.

13. (a) Reggelin, M.; Zur, C. Synthesis 2000, 1.

14. The reaction was also performed using microwave irradiation with no change in outcome.

15. (a) Klapers, A.; Antilla, J. C.; Huang, S. L.; Buchwald, S. L. J. Am. Chem. Soc. 2001, 123, 7727. (b) Klapers, A.; Huang, S. L.; Buchwald, S. L. J. Am. Chem. Soc. 2002, 124, 7421.

16. Singer, R. D.; Knochel, P. Chem. Rev. 1993, 93, 2117.

17. Monnier, F.; Taillefer, M. Angew. Chem. Int. Ed. 2009, 48, 6954.

18. Casitas, A.; King, A. E.; Parella, T.; Costas, M.; Stahl, S. S.; Ribas, X. Chem. Sci. 2010, 1, 326.

19. Zhang, X.; Larock, R. C. Org. Lett. 2005, 7, 3973.

20. Benzothiazine 4 shows absorption $\lambda_{(\max )}$ at $338 \mathrm{~nm}(\log \varepsilon=3.66)$ and emission $\lambda$ (emission) at $463 \mathrm{~nm}$ at $100 \mu \mathrm{M}$ concentration in $\mathrm{CHCl}_{3}$, at $25{ }^{\circ} \mathrm{C}$. The large Stokes shift is noteworthy.

21. (a) Drabowicz, J.; Lyzwa, P.; Popielarczyk, M.; Mikolajczyk, M. Synthesis 1990, 10, 937.

(b) Johnson, C. R.; Haake, M.; Schroeck, C. W. J. Am. Chem. Soc. 1970, 92(22), 6594. 